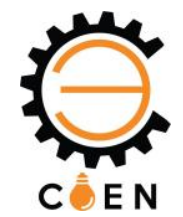

\title{
DESENVOLVIMENTO DE PROTÓTIPO PARA CONTROLE DE TEMPERATURA PARA AQUECEDORES HÍDRICOS
}

\author{
Heuler Andrade Silva ${ }^{(1)}$ (heulerasilva1607@ hotmail.com), Dênis Alves Teixeira Pereira $^{(1)}$ \\ (deteixeira89@gmail.com), Gustavo Lobato Campos ${ }^{(1)}$ (gustavo.lobato@ifmg.edu.br), Diego Luis Izidoro \\ Silva ${ }^{(1)}$ (diego.izidoro@ifmg.edu.br) \\ (1) Instituto Federal de Minas Gerais (IFMG) - Rua Padre Alberico, 440, São Luiz, Formiga - MG, 35570-000
}

RESUMO: - Este artigo apresenta o desenvolvimento de um protótipo de um controlador de temperatura para água oriunda do sistema de aquecimento solar. O sistema de aquecimento solar consiste em dois reservatórios, um contendo água a uma temperatura próxima a ambiente (caixa d'água) e outro contento água aquecida (boiler), desse modo, a água utilizada para consumo provem da mistura da vazão dos dois reservatórios. Logo a temperatura de água para consumo será resultado de um processo de equilíbrio térmico. $O$ processo até então manual, apresenta grande imprecisão, o que ocasiona elevado índice de desperdício. Desse modo, pretende-se através de um sistema de bombeamento e do controle de vazão de cada reservatório chegar à temperatura desejada para consumo. $O$ sistema de controle é composto por uma plataforma microcontrolada, além de sensores e atuadores. O presente trabalho apresenta a construção do protótipo, tendo em vista a elaboração do sistema embarcado e das válvulas proporcionais, além da disposição de todo sensoriamento. Além de apresentar os cálculos e aproximações utilizadas para embasamento e modelagem do sistema, conforme características literais de sistemas termodinâmicos. Como resultado final, o controle será apresentado ao usuário através de uma interface, afim de proporcionar como benefício a economia de água e energia, além de praticidade e conforto.

PALAVRAS-CHAVE: Aquecedor solar, automação, Arduino, válvula proporcional, termodinâmica.

\section{INTRODUÇÃO}

Em seu uso moderno, a automação pode ser definida como uma tecnologia que utiliza comandos programados para operar um dado processo, combinados com retroação de informação para determinar que os comandos sejam executados corretamente, frequentemente utilizada em processos antes operados por seres humanos. Trata-se ainda da aplicação de técnicas computadorizadas ou mecânicas para diminuir o uso de mão de-obra em qualquer processo ou aumentar a praticidade de um processo, cita-se como exemplo o uso um controlador para temperatura da água para sistemas de aquecedores solares (LACOMBE, 2004).

O limite da disponibilidade de energias fósseis e as ameaças ao meio ambiente levaram o homem a buscar fontes alternativas de energia que produzam pouco impacto ambiental, e a energia solar está entre elas. Esta fonte de energia limpa, entre outras aplicações, pode ser utilizada no aquecimento de água, para assim proporcionar economia no uso da energia elétrica (ORMENESE, 2009).

Assim, o artigo apresenta resultado de trabalho que aborda os dois tópicos mencionados nos parágrafos anteriores. Uma vez que tem por objetivo solucionar um problema comum encontrado em grande parte das residências que possuem um sistema de aquecimento da água para consumo. No 
atual cenário, ao economizar a energia destinada a chuveiros elétricos, usa-se formas alternativas de aquecimento da água, como aquecedores solares. O problema encontrado está relacionado ao desperdício de água ao abrir o registro do sistema, pois, há uma grande quantidade de água fria armazenada na tubulação, a qual é desperdiçada até o momento de chegada da água aquecida. Além disso o controle de vazão de cada reservatório é feito de forma manual, sendo pouco preciso, o que gera desperdícios até o usuário alcançar a temperatura desejada. Desse modo, surge a ideia desse protótipo, afim de retornar à água fria acumulada na tubulação para a caixa d'água, além de realizar um controle preciso de temperatura através da vazão dos reservatórios.

\section{REFERENCIAL TEÓRICO}

\subsection{Controlador}

As placas de interface Arduino propiciam uma tecnologia de baixo custo e de grande utilidade para o desenvolvimento de projetos eletrônicos. Esta placa de micro controlador que contém um conector USB que permite a conexão entre a placa Arduino e o computador, assim pode ser programado em linguagem $\mathrm{C}$. Além desta conexão, o Arduino possui diversas outras como diversos pinos permitindo a conexão com circuitos eletrônicos externos, como diodos, laser, alto-falantes, motores, servo motores, relés, sensores de diversos tipos, dentre outros (SIMON, 2014). Desse modo, o Arduino UNO, visto na Figura 1, é um dispositivo que facilita a prototipagem e implementação de controle de sistemas, pois pode enviar ou receber informação de diversos dispositivos eletrônicos.

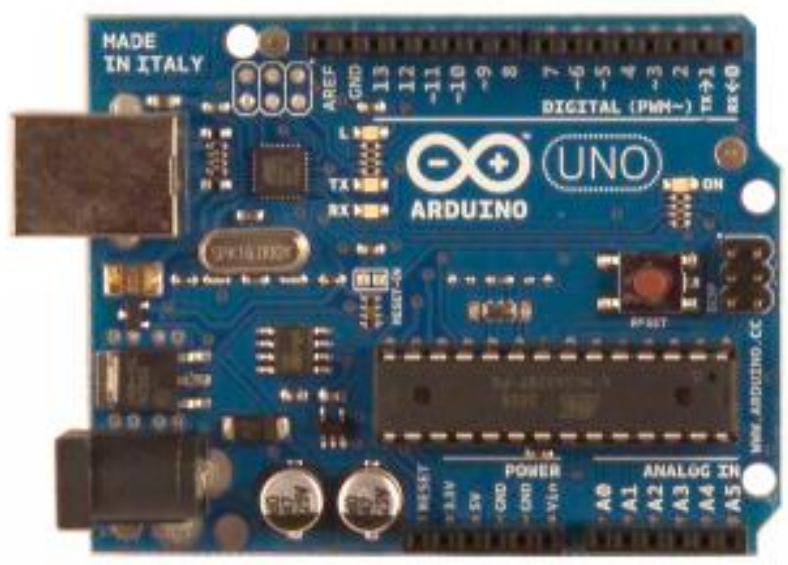

Figura 1. Controlador Arduino UNO (SOUZA, 2019).

O Arduino pode ser controlado diretamente pelo computador e ou programado pelo computador e, a seguir, sua programação é gravada no microcontrolador para poderem trabalhar de forma autônoma, considerado um projeto de hardware aberto (open-source) mas de grande poder para automação industrial, predial ou residencial (MCROBERTS, 2011).

Os principais componentes do Arduino UNO são os conectores de alimentação, conectores de tensão de referência interna e de saída, entradas e saídas digitais, entradas analógicas e outros 
componentes. Desse modo, no presente trabalho, o mesmo tem como finalidade processar sinais dos sensores, realizar o cálculo de operação e posteriormente comandar os atuadores.

\subsection{Atuador}

Os servos motores, como o visto na Figura 2, são motores elétricos que possuem alta precisão nos movimentos realizados através da transformação da energia elétrica em energia mecânica. Os servos motores são utilizados principalmente em aplicação da área da robótica que exigem de uma precisão alta em movimentos lineares ou rotativos (MARTINEWSKI, 2016).

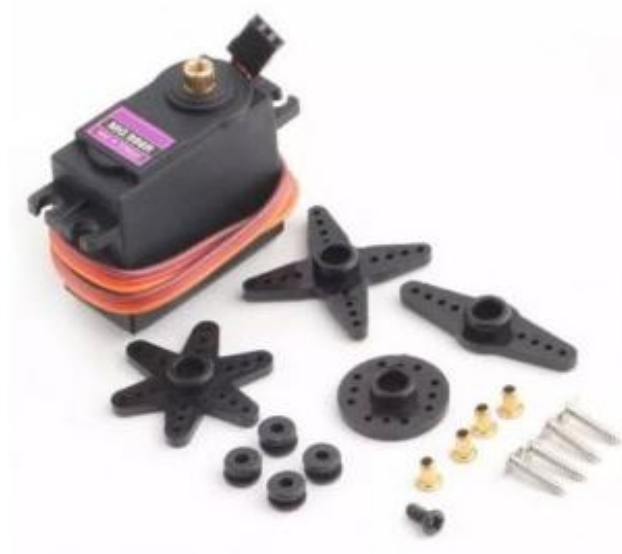

Figura 2. Servo motor TowerPro MG996R (TOWERPRO, 2019).

O servo motor de corrente contínua CC, é o conjunto de quatro componentes principais, sendo eles: motor de corrente contínua; dispositivo de detecção de posição; conjunto de engrenagens que possam gerar maior torque para o sistema e um circuito eletroeletrônico de controle. Geralmente, este sistema pode ser controlado por um gerador de largura de pulso - PWM (Pulse Width Modulation) que se refere ao conceito de pulsar rapidamente um sinal digital em um condutor. $\mathrm{O}$ sistema dos servos motores controlados por PWM, tem o objetivo de controlar a tensão de referência da corrente contínua para o valor correspondente à saída desejada (CARVALHO, 2011). As especificações do servo motor da TowerPro modelo MG996R, estão dispostas na Tabela 1 (TOWERPRO, 2019).

Tabela 1. Especificações servo motor MG996R

\begin{tabular}{|c|c|c|c|}
\hline Parâmetro & Mínimo & Máximo & Unidade \\
\hline Tensão de alimentação & 3 & 5.5 & VDC \\
\hline Corrente de operação & 500 & 900 & $\mathrm{~mA}$ \\
\hline Torque & $9,4(\mathrm{a} 4.8 \mathrm{~V})$ & $11(\mathrm{a} 6 \mathrm{~V})$ & $\mathrm{kg} . \mathrm{cm}$ \\
\hline Temperatura de operação & 0 & 55 & ${ }^{\circ} \mathrm{C}$ \\
\hline \multicolumn{3}{|c|}{ Velocidade $\mathbf{0 . 1 4} \mathbf{~ s e g / 6 0 ^ { \circ }}(\mathbf{6 V})$} \\
\hline \multicolumn{4}{|c|}{ Corrente stall $\mathbf{2 . 5}^{\mathbf{a}}$} \\
\hline
\end{tabular}



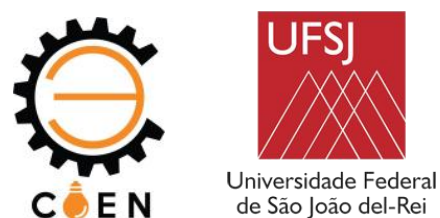

Neste projeto será utilizado um controlador de largura de pulso (PWM) para o acionamento controlado do dispositivo de atuação linear que definirá a porcentagem referente a angulação desejada de abertura das válvulas proporcionais.

\subsection{Sensor}

Os sensores de temperatura são dispositivos que ajudam a identificar o nível de aquecimento de um determinado equipamento ou processo. Dentre os modelos de sensores de temperatura disponíveis no mercado, temos o modelo DS18B20 da Dallas Instruments.

O diferencial desse sensor é que o mesmo possui sua própria inteligência. Ele é capaz de ler a temperatura, interpreta-la e enviar a informação do valor de temperatura em graus Celsius para o microcontrolador usando um barramento de apenar um fio (protocolo de comunicação one wire), o esquema de ligação do sensor é visto na Figura 3.

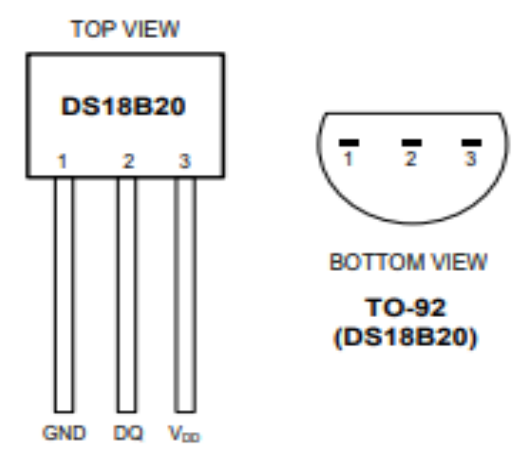

Figura 3. Sensor DS18B20 (MAXIMINTEGRATED, 2019).

O termômetro digital DS18B20 se comunica através de um barramento de um único fio que, por definição, requer apenas uma linha de dados (e terra) para comunicação com uma central microprocessador. Além disso, o DS18B20 pode derivar energia diretamente da linha de dados ("poder parasita"), eliminando a necessidade de uma fonte de alimentação externa. Cada DS18B20 possui um código serial exclusivo de 64 bits, permite que múltiplos DS18B20s funcionem no mesmo barramento. Os parâmetros de operação e leitura do sensor são dispostos na Tabela 2 (MAXIMINTEGRATED, 2019).

Tabela 2. Especificações sensor DS18B20

\begin{tabular}{|c|c|c|c|}
\hline Parâmetro & Mínimo & Máximo & Unidade \\
\hline Tensão de alimentação & 3 & 5.5 & VDC \\
\hline Faixa de medição & -55 & 125 & ${ }^{\circ} \mathrm{C}$ \\
\hline \multicolumn{3}{|c|}{ Resolução 9 ou 12 bits } \\
\hline \multicolumn{3}{|c|}{ Precisão de $\pm \mathbf{0 . 5} \mathbf{C}^{\circ} \mathbf{C d e}-\mathbf{- 1 0}^{\circ} \mathbf{C}$ a $\mathbf{+ 8 5}^{\circ} \mathbf{C}$} \\
\hline
\end{tabular}

Desse modo, faz-se necessária a utilização de três sensores DS18B20, um para monitoramento do tanque de água quente, outro para monitoramento do tanque de água fria e por fim um para monitoramento da temperatura dá água utilizada para consumo. A principal vantagem desse sensor é 
que ele pode ser adquirido com um encapsulamento metálico, oferecendo assim uma proteção à prova d'água, fazendo com que o mesmo possa ser submerso no líquido em questão.

\subsection{Válvula tipo esfera}

Válvulas são dispositivos utilizados para controlar o fluxo de fluido em tubulações. Desse modo, a válvula tipo esfera é um dispositivo mecânico, que controla a vazão que passa no seu interior, através de um obturador esférico, representado na Figura 4.

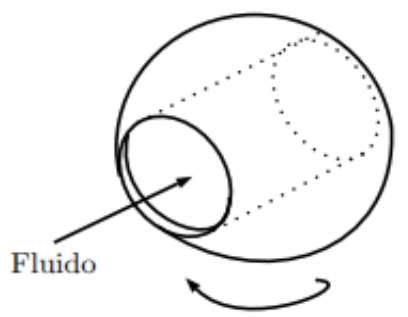

Figura 4. Obturador esférico (FERNANDES, 2018).

A válvula tipo esfera possui sua operação compreendida em um intervalo de $90^{\circ}$, permitindo assim, uma pequena mudança na direção da vazão dentro do corpo da válvula, consequentemente ocorre uma pequena queda de pressão. Essas válvulas possuem como benefícios o baixo custo e ausência de um espaço vertical para deslocamento, quando comparada a demais válvulas presentes no mercado, além de que a abertura da válvula e a vazão podem ser determinadas muito precisamente. Portanto, válvulas tipo esfera se tornam adequadas para controle proporcional. A desvantagem de se utilizar uma válvula desse tipo é que sua característica é não linear, conforme visto na Figura 5, um gráfico do comportamento da válvula tipo esfera, relacionando o percentual de vazão por percentual de abertura.

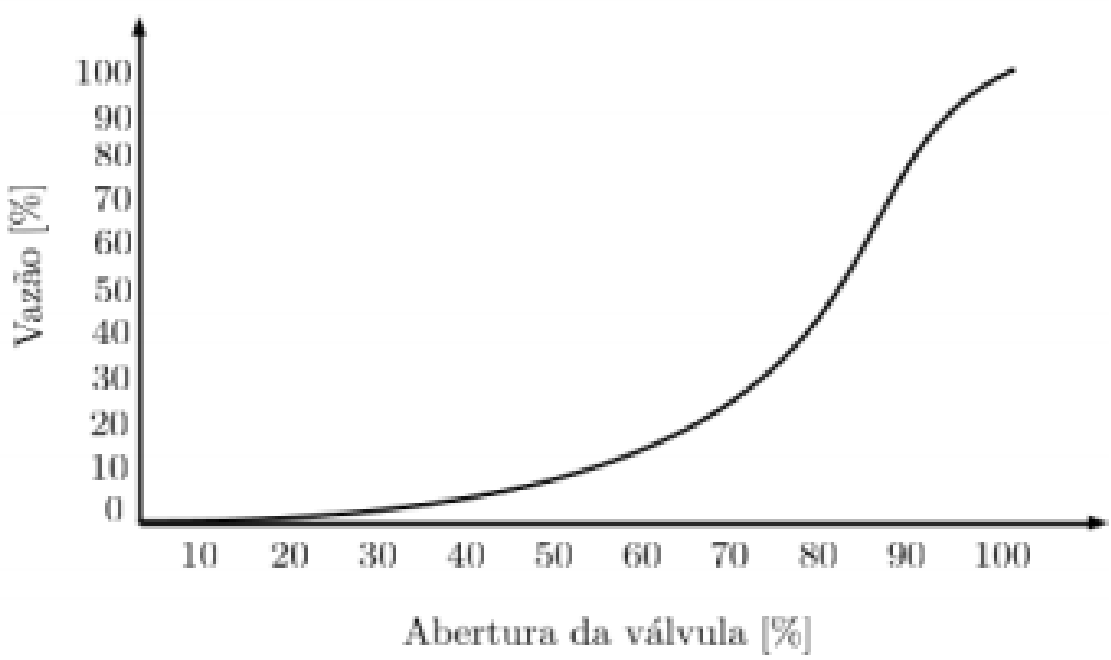

Figura 5. Gráfico da relação de percentual da vazão máxima × percentual de abertura da válvula tipo esfera (MEYER, 2019). 
A válvula utilizada neste trabalho é da marca WOG, com alavanca e bitola 1/2". É importante lembrar que esse modelo de válvula é $1 / 4$ de volta, ou seja, a válvula tem limites de abertura no intervalo de $0^{\circ}$ a $90^{\circ}$. Portanto, tomando-se como referência o corpo da válvula como $0^{\circ}$, ela se encontra totalmente fechada quando se obtém um ângulo de $90^{\circ}$. Sendo assim, no ângulo de $0^{\circ}$ está totalmente aberta.

\section{MODELAGEM DO SISTEMA}

O sistema pode ser modelado como um volume de controle em regime permanente sendo este regido pela primeira lei da termodinâmica para balanços de massa e energia.

\subsection{Balanço de massa}

O balanço de massa (ou material) se baseia no princípio de conservação da massa, sendo feito através da contabilidade de material que entra e deixa um sistema determinado por uma fronteira, seja ela uma corrente, um equipamento ou processo. A aplicação do mesmo depende do contexto do problema em análise, mas é regido pelo fato de que matéria não pode desaparecer e nem ser criada (JUNIOR, 2010). O balanço de massa em regime permanente é regido pela Equação 1 (HIBBELER, 2016).

$$
\sum m_{e}=\sum m_{s}
$$

Onde " $m_{e}$ " é a massa que entra no sistema e " $m_{s}$ " é a massa que saí do sistema. Desse modo, o sistema em estudo é formado por 2 entradas e 1 saída, conforme visto na Figura 6.

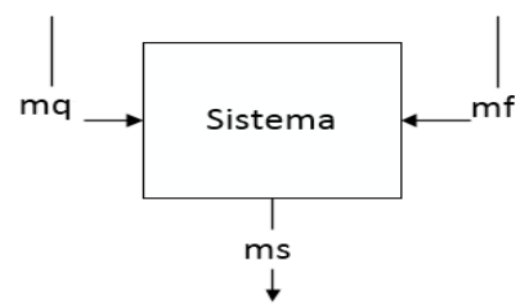

Figura 6. Modelagem do sistema. Próprio autor.

Onde "mq" representa a massa de água quente que entra no sistema, assim como "mf" representa a massa de água fria que também entra no sistema, enquanto que "ms" representa a massa de água que sai do sistema para consumo.

Além disso, em baixas variações de temperatura, a água, tem sua vazão mássica próxima a vazão volumétrica, considerando assim que ambas possuem mesmo valor, é possível chegar na Equação 2, que modela o sistema através do balanço de massa.

$$
\stackrel{\bullet}{V}_{f}+\dot{V}_{q}=\dot{\bullet}_{s}
$$

Onde $\dot{V}_{f}$ é a vazão de água fria, $\dot{V}_{q}$ a vazão de água quente e $\dot{V}_{s}$ a vazão da saída do sistema. 


\subsection{Balanço de energia}

Embora a energia assuma várias formas, a quantidade de energia é constante e, quando energia em uma forma desaparece, ela reaparece simultaneamente em outras formas, e é contabilizada pela diferença entre o trabalho realizado e o calor fornecido ao mesmo (FELDER, 2005). Desse modo, é possível adotar a Equação 3 de balanço de energia para modelagem do sistema (HIBBELER, 2016).

$$
\dot{Q}-W=\sum \dot{m}_{e}\left[h_{e}+\frac{V_{e}^{2}}{2}+g\left(z_{e}\right)\right]-\sum \dot{m}_{s}\left[h_{s}+\frac{V_{s}^{2}}{2}+g\left(z_{s}\right)\right]
$$

Onde $\dot{Q}$ é o fluxo de calor, W o trabalho, $\dot{m}_{e}$ a vazão mássica de entrada, $\dot{m}_{s}$ a vazão mássica de saída, $h_{e}$ é a entalpia do fluído de entrada, $h_{s}$ a entalpia do fluído de saída, $V_{e}$ a velocidade do fluído de entrada, $V_{s}$ a velocidade do fluído de saída, $g$ a gravidade, $z_{e}$ a altura de fluído de entrada e $z_{s}$ a altura de fluído de saída. O sistema presente não apresenta trabalho, além disso, através de considerações adotadas, desprezando a variação de altura e de velocidade, além de desconsiderar que haja fluxo de calor do sistema com o ambiente, é possível chegar na Equação 4.

$$
\dot{Q}=\dot{m}_{f} h_{f}+\dot{m}_{q} h_{q}-\dot{m}_{s} h_{s}
$$

Onde $\dot{m}_{f}$ é a vazão mássica de água fria, $\dot{m}_{q}$ é a vazão mássica de água quente, $\dot{m}_{s}$ é a vazão mássica da água de saída, $h_{f}$ é a entalpia da água fria, $h_{q}$ é a entalpia da água quente e $h_{s}$ é a entalpia da água de saída.

Por definição, considerando que a pressão no fluido seja constante, rege a Equação 5.

$$
C_{p}=\frac{d H}{d T}
$$

Onde $C_{p}$ é o calor específico do fluido, $d h$ é a variação de entalpia e $d T$ a variação de temperatura. Como a variação de temperatura da água do sistema é considerada relativamente baixa, o calor específico pode ser considerado constante. Além disso, em baixas variações de temperatura, a água, tem sua vazão mássica próxima a vazão volumétrica, considerando assim que ambas possuem mesmo valor. Chegando assim na Equação 6, que modela o sistema através de balanço de energia.

$$
0=\dot{V}_{f} T_{f}+\dot{V}_{q} T_{q}-\dot{V}_{s} T_{s}
$$

Onde $T_{f}$ a temperatura do reservatório de água fria, $T_{q}$ a temperatura do reservatório de água quente, e $T_{s}$ a temperatura da água de saída.

3.3 Balanço de massa e energia

Através das considerações utilizadas e do balanço de massa, demostrado na Equação 2 e do balanço de energia, visto na Equação 6, é possível então relacionar as equações em um sistema onde 
se obtém como resultado a Equação 7 que expressa a vazão do reservatório de água fria e a Equação 8 que expressa a vazão do reservatório de água quente.

$$
\begin{aligned}
& V f=\frac{V s(T s-T q)}{T f-T q} \\
& V q=\frac{V s(T f-T s)}{T f-T q}
\end{aligned}
$$

Adotando a vazão volumétrica de saída do sistema "Vs" como máxima, definida como $0,0001067 \mathrm{~m}^{3} / \mathrm{s}$ (FERNANDES, 2018), tem-se então as duas equações que regem o sistema (HIBBELER, 2016).

\section{DESENVOLVIMENTO}

O projeto foi desenvolvido conforme apresentado no esquemático da Figura 7.

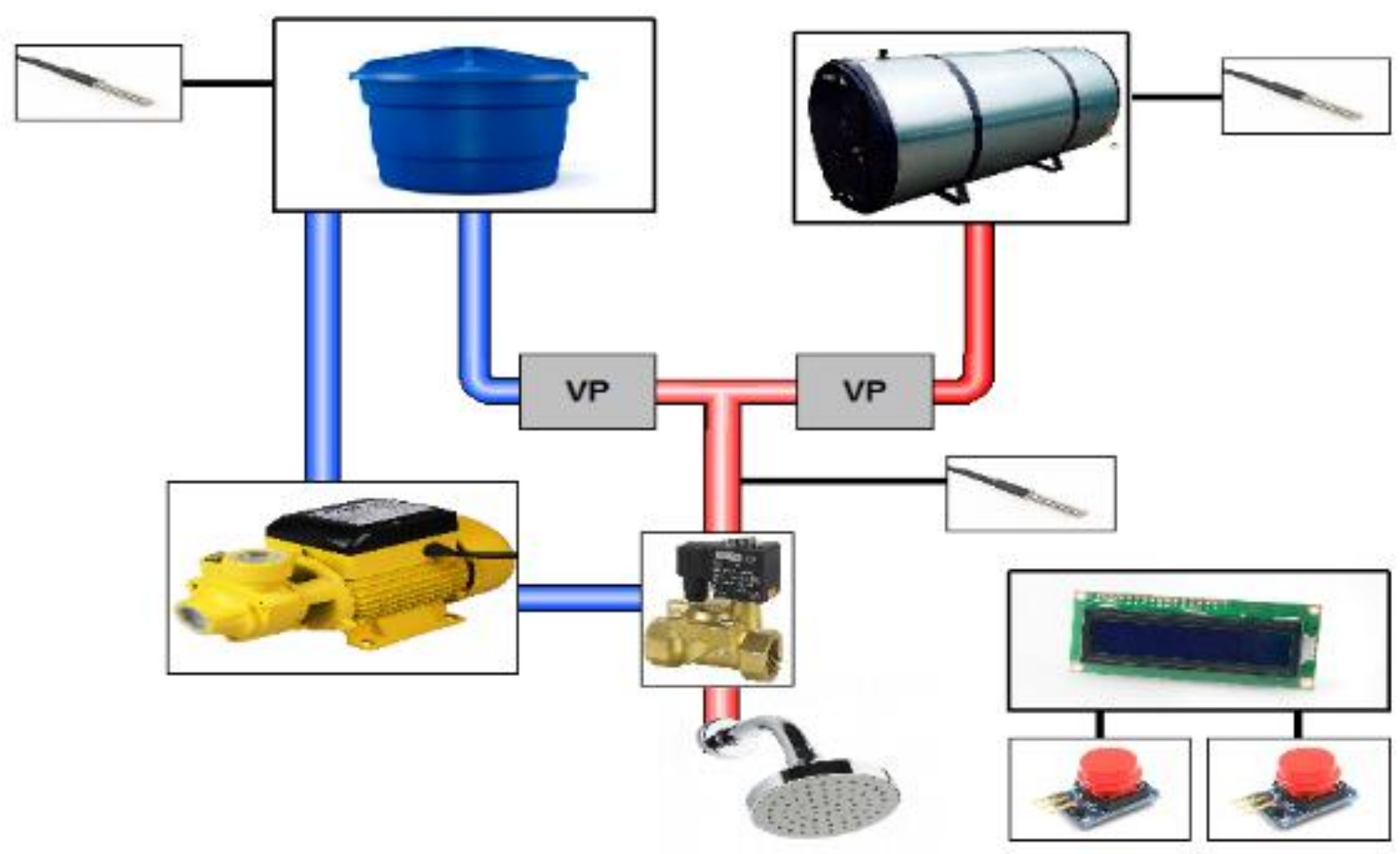

Figura 7. Esquemático do sistema. Próprio autor.

Onde, conforme a Figura 1, o sistema pode ser divididos em cinco partes, na primeira é relacionado aos reservatórios, um de água aquecido (boiler) e outro de água em temperatura ambiente (caixa d'água), a segunda parte é relacionada a interface, a mesma é composta por uma tela LCD e

$$
\begin{array}{r}
\text { IX COEN - Congresso de Engenharias da UFSJ } \\
\text { Interconexão. }
\end{array}
$$


botões para regulagem do setpoint (valor desejado), a terceira parte trata-se do sensoriamento do sistema, composta pelos três sensores de temperatura, na quarta parte temos os atuadores, composta pelas duas válvulas proporcionais, a bomba d'água, e válvula solenoide e por último temos a quinta parte, definida como senso o sistema de controle, composta pelo controlador.

\subsection{Válvula proporcional}

A confecção da válvula proporcional se dá por meio do acoplamento do servomotor com a válvula esférica, para tal foi necessário a construção de um sistema de acoplamento. O servomotor comprado acompanha peças de acoplamento, entre essas foi utilizada a apresentada na Figura 8.

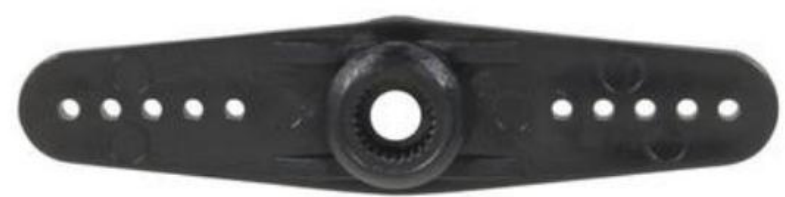

Figura 8. Peça de acoplamento. Próprio autor.

Desse modo, foi desenvolvido uma placa de metal para unir os dois componentes, como visto na Figura 9.

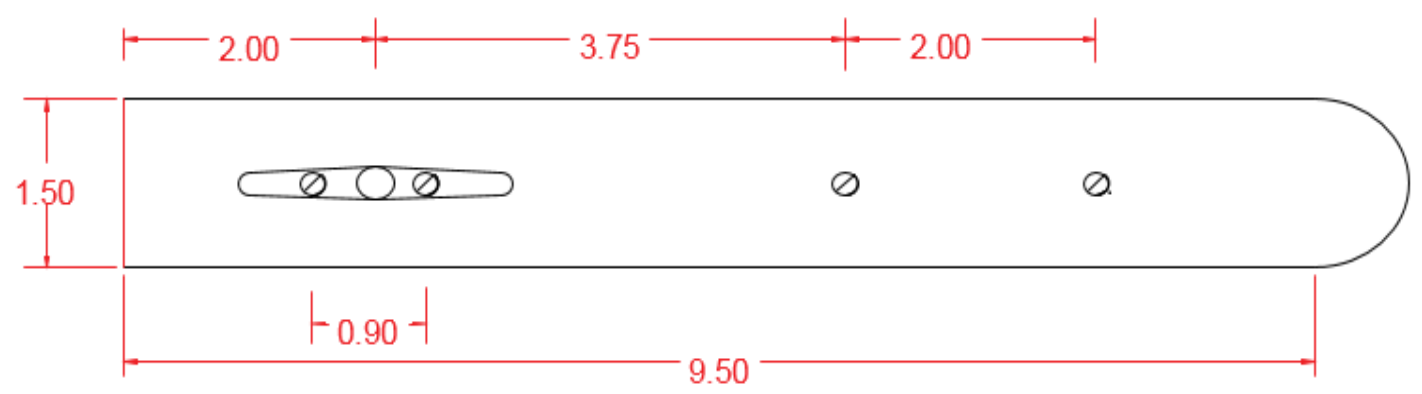

Figura 9. Placa de acoplamento em CAD. Próprio autor.

A chapa de metal possui dimensões apresentadas conforme Figura 9, possuindo formato idêntico ao da alavanca, permitindo maior facilidade para o acoplamento onde também estão representados a localização da peça de acoplamento e o posicionamento de uma junção necessária para acoplar a alavanca do registro, essas junções, tanto da peça quanto da alavanca do registro, foram feitas por meio de um conjunto de quatro parafusos e porcas.

Para funcionamento correto do sistema, tanto o registro quanto o servomotor precisam ser fixados em uma mesma referência, nesse sentido, o corpo da válvula e a carcaça do servo precisam estar fixados a um mesmo referencial, desse modo ambos devem ser fixados em uma mesma estrutura para que a alavanca possa completar o movimento de $0 \circ \mathrm{a} 90^{\circ}$, ou seja, apenas a alavanca da válvula deve acompanhar o giro do servo. Sendo assim, foi projetado uma placa de aço, onde suas dimensões são apresentadas na Figura 10. 


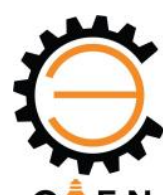

C $\mathrm{EN}$

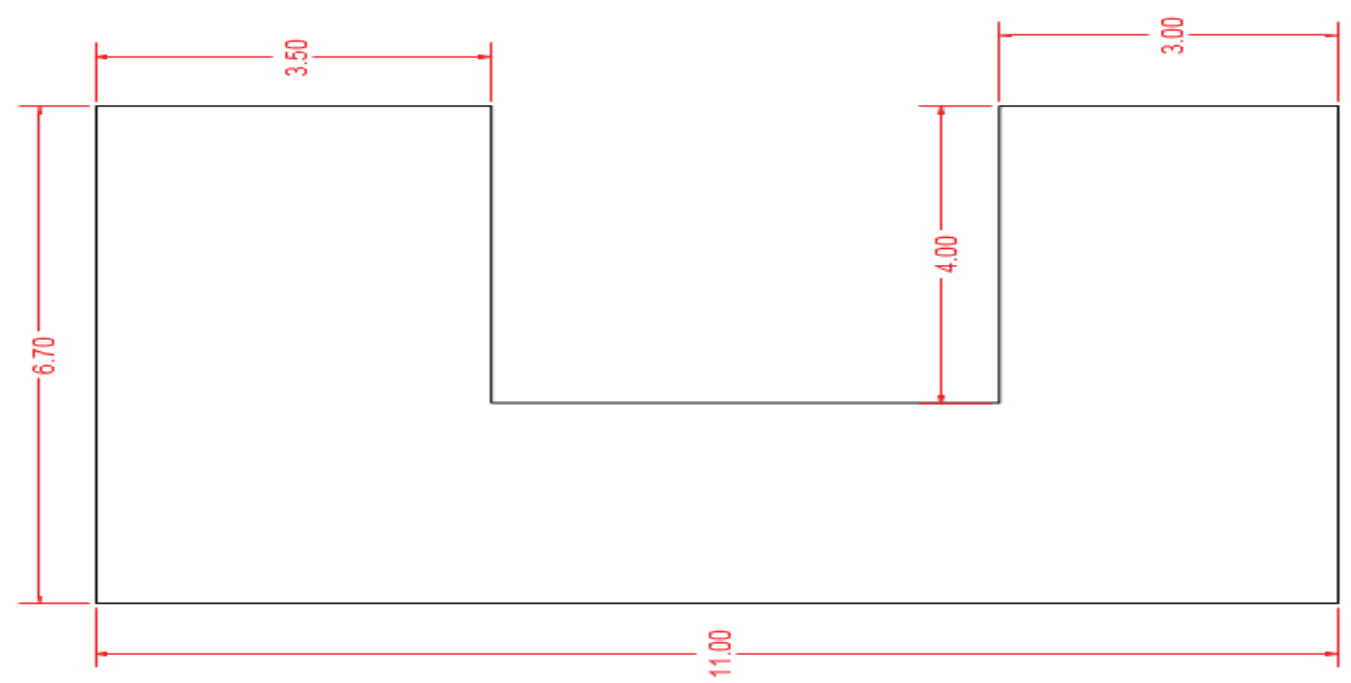

Figura 10. Placa de suporte em CAD. Próprio autor.

A estrutura final da válvula proporcional é apresentada na Figura 11.

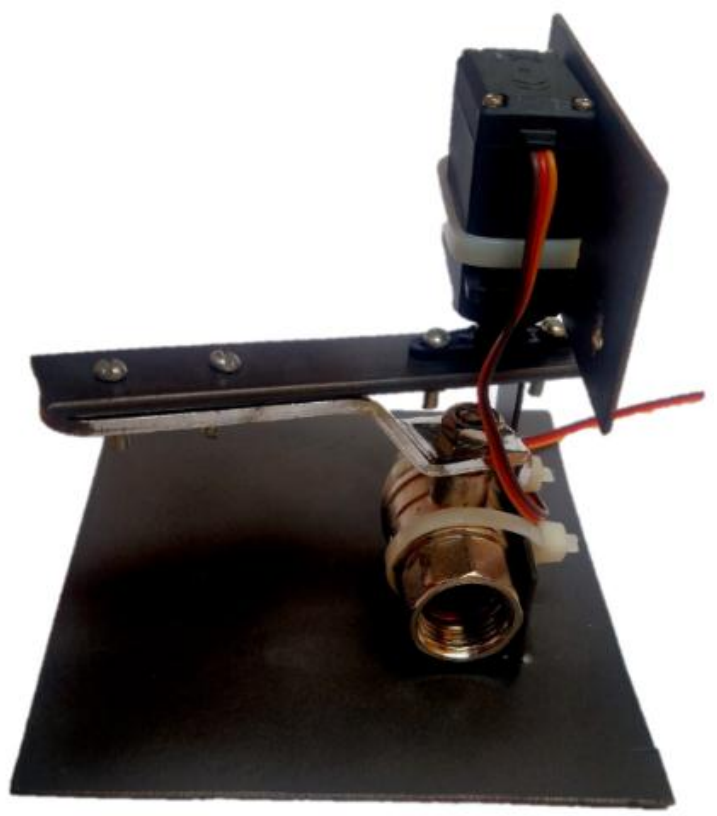

Figura 11. Válvula proporcional. Próprio autor.

A válvula então é controlada pela plataforma Arduino, podendo variar seu ângulo de rotação entre $0^{\circ}$ (registro fechado) e $90^{\circ}$ (vazão máxima). O servomotor realizará o torque necessário $(13 \mathrm{~kg} . \mathrm{cm})$ para realizar o giro no obturador da válvula. Para realizar o rotacionamento do obturador foi utilizado uma fonte externa de $5 \mathrm{~V}$ com corrente até $10 \mathrm{~A}$, pois a plataforma Arduino não fornece uma corrente necessária para atuação do servomotor, conforme datasheet (TOWERPRO, 2019). 


\subsection{Interface}

A interface de controle é vista na Figura 12, onde em uma caixa reaproveitada de um módulo para sistema de luz de emergência, são inseridas nas mesmas o controlador Arduino, além da tela LDC e os botões de controle.

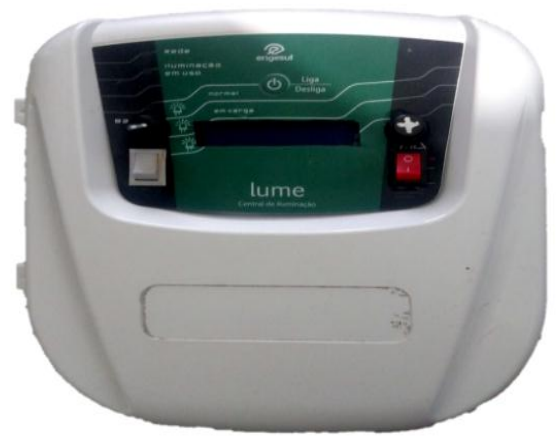

Figura 12. Interface. Próprio autor.

A interface é composta por duas chaves ON/OFF, dois botões de pulso, três LED's e uma tela LCD. A tela LCD apresenta seis pinos para realizar comunicação com algum controlador, desse modo, afim de reduzir o número de portas de ligação, foi utilizado um módulo IC2 que fornece expansão de entradas e saídas por meio de duas conexões bidirecionais (NXP, 2019), desse modo foi possível reduzir seis portas para apenas duas.

Assim que o sistema é ligado, um LED verde é acesso, e assim que a chave ON/OFF de cor vermelha é acionada, um LED amarelo é acesso, além disso os botões de pulso são ativados para regulagem da temperatura desejada. A temperatura máxima possível é a mesma que a do tanque de água aquecida, assim como a temperatura mínima corresponde a temperatura do tanque de água fria. Desse modo a faixa de regulagem corresponde a um valor entre as temperaturas mínima e máxima.

Após escolha da temperatura, basta acionar a chave ON/OFF de cor branca para dar partida no sistema, desse modo, um LED de cor vermelha é aceso para demostrar que o sistema está em execução. O microcontrolador então calcula a vazão de cada válvula proporcional através da Equação 7 e Equação 8, por fim a válvula solenoide é aberta e a bomba acionada para retorno da água armazenada na tubulação para o reservatório de água fria, posteriormente as válvulas proporcionais são acionadas conforme a vazão então calculada. Caso durante a operação o usuário deseja alterar o valor da temperatura, basta desligar a chave branca, selecionar a nova temperatura desejada e acionar a chave branca novamente, dando partida no sistema.

Para desligar o módulo basta desligar a chave vermelha, fazendo que interrompa a alimentação do sistema.

\subsection{Programação}

Através de um esquema de ligação feito em CAD, feito no software Fritzing, como visto na Figura 12. Foi possível então definir as portas do controlador que seriam utilizadas por cada dispositivo. 


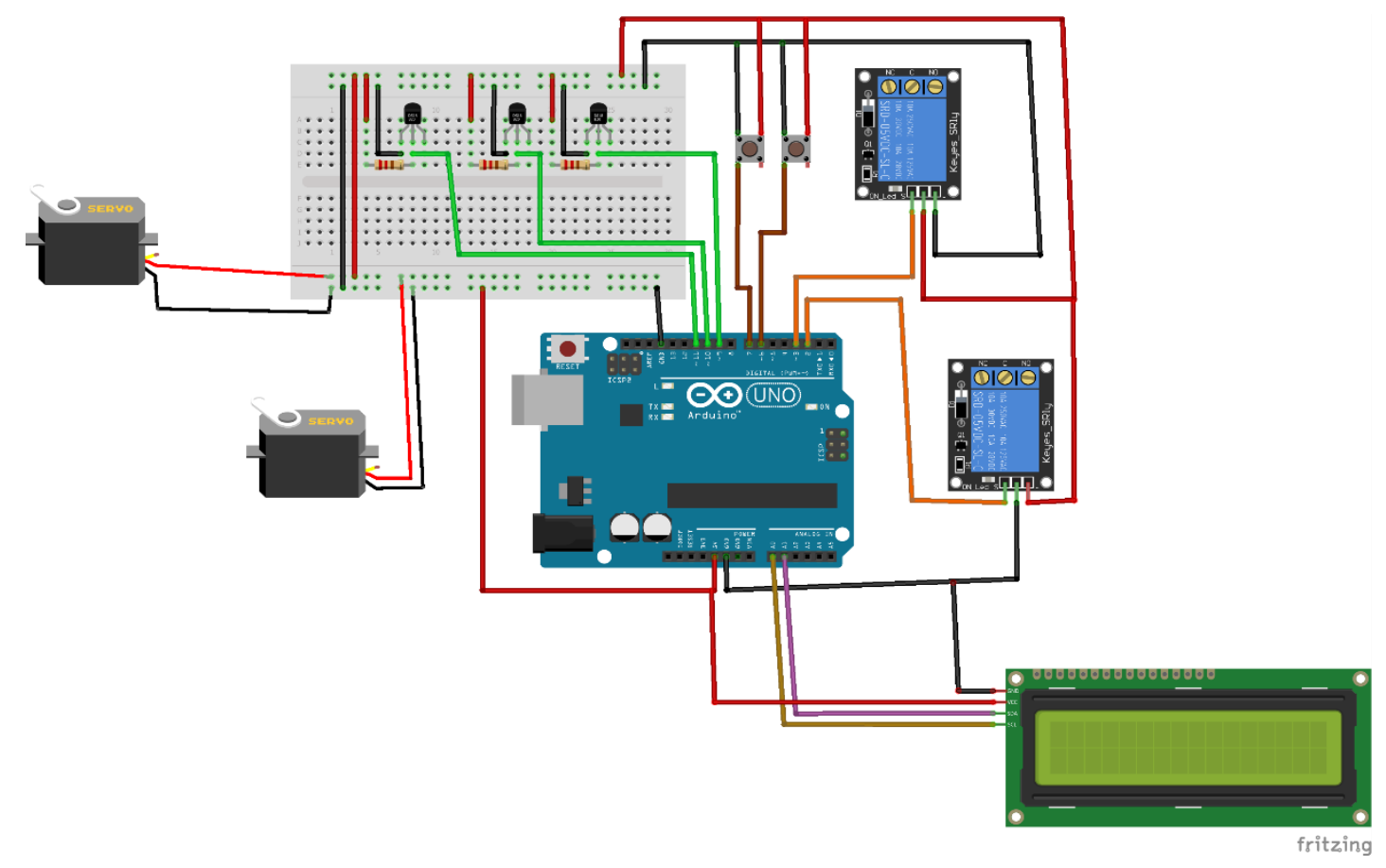

Figura 12. Representação do sistema em CAD. Próprio autor.

Através das portas escolhidas no microcontrolador, foi possível a programação do sistema, onde as bibliotecas necessárias são apresentadas na Figura 13.

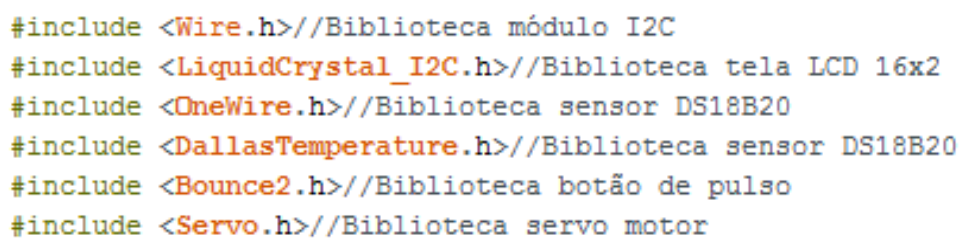

Figura 13. Bibliotecas. Próprio autor.

Onde a biblioteca "Wire" foi utilizada para comunicação do módulo I2C acoplado à tela LCD, a biblioteca "LiquidCrystal_I2C" foi utilizada para configuração da tela LCD, as bibliotecas "OneWire" e "DallasTemperature" foram utilizadas para comunicação entre a plataforma e os sensores de temperatura DS18B20, a biblioteca "Bounce2" foi utilizada para parametrização dos botões de pulso utilizados, por fim, a biblioteca "Servo" foi utilizada para controlar o servomotor.

\section{RESULTADOS}

Para a realização de testes a interface foi conectada às válvulas proporcionais, para representar o acionamento da válvula solenoide e da bomba d'água foram usados relés, onde tal funcionamento é visto quando as luzes do relé acendem. Através da Figura 14 é possível ver a representação do sistema final. 


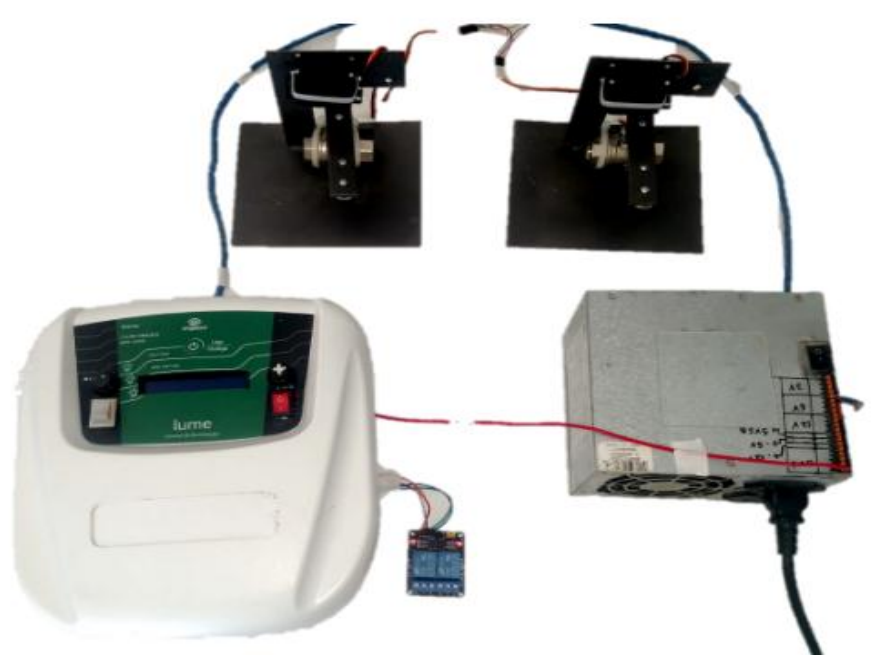

Figura 14. Protótipo. Próprio autor.

Após ligação de todo o sistema, o mesmo foi testado em bancada, adotando a temperatura do reservatório de água fria como sendo a temperatura lida pelo sensor, de $26^{\circ} \mathrm{C}$, e definindo um valor para a temperatura do reservatório de água aquecida, que nesse caso foi de $70^{\circ} \mathrm{C}$.

Afim de validar o sistema, valores de temperatura foram inseridos no painel, onde a Figura 15 representa a temperatura escolhida de $70^{\circ} \mathrm{C}$, sendo assim a válvula de água quente abre $100 \%$ enquanto que a válvula do tanque de água fria permanece fechada. Para o segundo teste, como visto na Figura 16, foi escolhida uma temperatura de $58^{\circ} \mathrm{C}$, desse modo o sistema definiu a abertura da válvula do reservatório de água quente em aproximadamente $72 \%$, e a válvula do reservatório de água fria em $28 \%$.

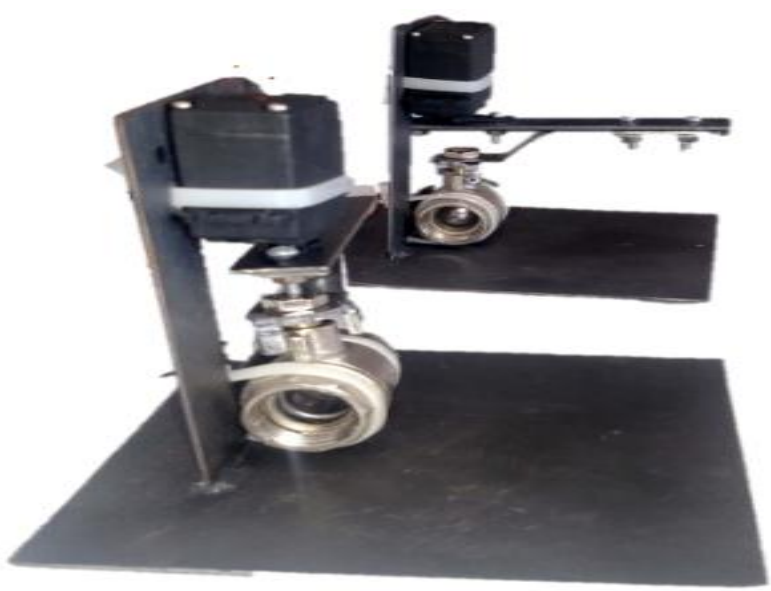

Figura 15. Atuação válvulas para $70^{\circ} \mathrm{C}$. Próprio autor.

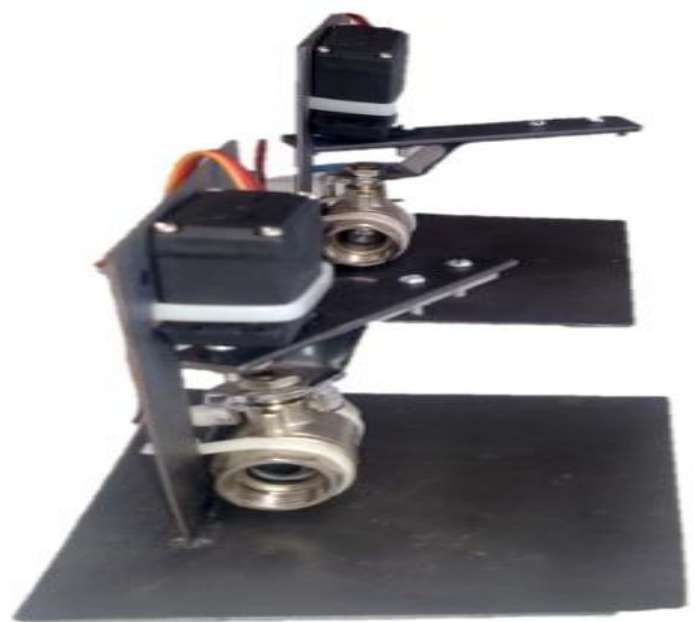

Figura 14. Atuação das válvulas para $58^{\circ} \mathrm{C}$. Próprio autor.

A vazão máxima de cada válvula corresponde a uma angulação de $90^{\circ}$ em relação à origem, desse modo a porcentagem obtida deve ser sobre a angulação de $90^{\circ}$ para assim definir o ângulo de 

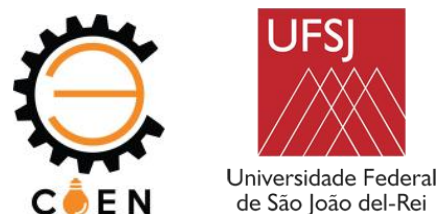

atuação de cada válvula correspondente a porcentagem calculada, para validação do sistema, um sensor disponível na saída mostra se a temperatura desejada foi realmente a obtida.

\section{CONCLUSÃO}

Este artigo apresenta os primeiros resultados de desenvolvimento de um protótipo de controlador de temperatura. O trabalho desenvolvido atingiu alguns objetivos preliminares, como a ampliação do conhecimento em termodinâmica, mecânica, elétrica e programação em Arduino.

Este projeto ressalta a importância da automação residencial, na qual com o controlador pode ter uma redução significativa do desperdício água ao se tomar banho e também otimizou o processo de controle de vazão para conseguir a temperatura desejável, ocasionando numa maior praticidade.

Desse modo, para trabalhos futuros, é esperado a realização de testes do sistema em campo com o emprego de uma válvula solenoide e de uma bomba d'água. Além disso, almejando alcançar uma maior precisão do sistema, poderia ser empregado válvulas medidoras de vazão para assim considerar fatores como a diferença de altitude e pressão, além de demais forças atuantes nos reservatórios, além da implementação de um controle PID para melhorar a precisão do sistema, minimizando as perdas e desconsiderações que podem acarretar numa baixa variação da temperatura escolhida e da temperatura obtida. Por fim, vale ressaltar a importância do emprego da engenharia para garantir segurança e qualidade de vida da população em geral.

\section{REFERÊNCIAS}

CARVALHO, G. Máquinas elétricas: teoria e ensaios. 4. ed. São Paulo: Érica, 2011.

FELDER, R.M., Rousseau, R.W. Princípios Elementares dos Processos Químicos.

Editora Ltc. $3^{\text {a }}$ edição. 2005.

FERNANDES, P. Projeto, construção e implementação de uma válvula proporcional para controle de nível em um tanque. 2018.

HIBBELER, R. C. Mecânica dos fluidos. Sã Paulo: Pearson Education do Brasil, 2016.

JUNIOR, A.C.B.; CRUZ, A.J.G. Fundamentos de Balanço de Massa e Energia. Editora EdUFSCar. 2010.

LACOMBE, F. “Dicionário básico da administração,” São Paulo: Saraiva, vol. 13, 2004.

MARTINEWSKI, A. Máquinas elétricas: geradores, motores e partidas. São Paulo: Érica, 2016.

MAXIMINTEGRATED. Datasheet sensor DS18B20. Disponível em <https://datasheets.maximintegrated.com/en/ds/DS18B20.pdf >. Acesso em: 04 jun. 2019. 

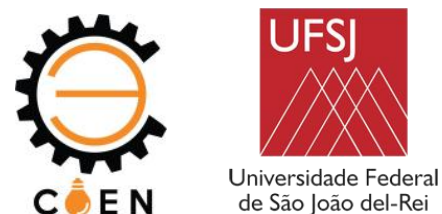

MEYER, D. Rubber-seated ball valve replacement saves energy, money and downtime. 2011. Disponível em: <https://www.pumpsandsystems.com/topics/valves/ball-valve-replacementincreases-savings >. Acesso em: 04 jun. 2019.

MCROBERTS, M. Arduino básico. São Paulo: Novatec, 2011. v. 1.

ORMENESE, Marcela et al. Controlador fuzzy para otimização de sistemas de aquecimento de água com coletores solares. 2009.

SIMON, M. 30 Projetos com arduino. Tradução: Antólio Laschuk. 2. ed. Porto Alegre: Bookman, 2014

TOWERPRO. Servomotor MG996R. Disponível em: <http://www.towerpro.com.tw/product/mg996r/>. Acesso em: 04 jun. 2019.

WOG. Válvula esfera WOG. Disponível em: 〈https://wog.com.br/>. Acesso em: 04 jun. 2019.

NXP. Semiconductors . Disponível em: <https://www.nxp.com/docs/en/datasheet/PCF8574_PCF8574A.pdf>. Acesso em: 04 jun. 2019.

\title{
PROTOTYPE DEVELOPMENT FOR TEMPERATURE CONTROL FOR WATER HEATERS
}

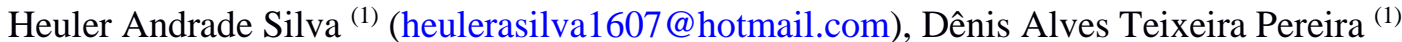 \\ deteixeira89@gmail.com), Gustavo Lobato Campos ${ }^{(1)}$ (gustavo.lobato@ifmg.edu.br), Diego Luis Izidoro \\ Silva ${ }^{(1)}$ (diego.izidoro@ifmg.edu.br) \\ (1) Instituto Federal de Minas Gerais (IFMG) - Rua Padre Alberico, 440, São Luiz, Formiga - MG, 35570-000
}

ABSTRACT: This work consists of the development of a prototype of a temperature controller for water from the solar heating system. The solar heating system consists of two reservoirs, one containing water at a temperature close to the environment (water tank) and another containing boiler water, so that the water used for consumption comes from mixing the flow of the two reservoirs, thus having a water temperature for consumption, resulting from a thermal equilibrium process. The process hitherto manual, presents great imprecision, which causes a high rate of waste. In this way, it is intended through a pumping system and the flow control of each reservoir to reach the desired temperature for consumption. The control system consists of a microcontrolled platform, as well as sensors and actuators. The present work presents the construction of the prototype, in view of the elaboration of the embedded system and the proportional valves, besides the provision of all sensing. In addition to presenting the calculations and approximations used for basing and modeling the system, according to literal characteristics of thermodynamic systems. As a final result, the control will be presented to the user through an interface, in order to provide the benefit of water and energy savings, as well as practicality and comfort.

KEYWORDS: Solar heater, automation, Arduino, proportional valve, thermodynamics. 